\title{
The Mathematical State of Equations of State ${ }^{\dagger}$
}

\author{
Abraham Marmur \\ Department of chemical engineering, Technion Israel Institute of Technology, Haifa, Israel \\ + Presented at the Entropy 2021: The Scientific Tool of the 21st Century, 5-7 May 2021; Available online: \\ https://sciforum.net/conference/Entropy2021/. \\ Published: 5 May 2021
}

The van der Waals equation of state was a breakthrough of a genius. However, while it was a masterpiece from a conceptual point of view, it is not quantitatively accurate. Many equations of state have been proposed to date, the accuracy of which has been improved by introducing temperaturedependence of coefficients, and various ways to treat the volume of the molecules themselves. Long time ago, the author analyzed the mathematical aspects of equations of state and proved that the general form must be $\mathrm{P}=\mathrm{A}(\mathrm{V}) \mathrm{T}-\mathrm{B}(\mathrm{V})$, where $\mathrm{P}$ is the pressure, $\mathrm{T}$ is the absolute temperature, $\mathrm{V}$ is the volume, and $\mathrm{A}$ and $\mathrm{B}$ are functions of $\mathrm{V}$ only. Thus, the corrections to the van der Waals equation should depend on the volume only and not on the temperature. Practical implications of this conclusion are demonstrated.

Another major problem is the construction of equations of state of mixtures. The prevalent approach is to define mixing rules for the parameters of the equation of state, by which the mixture is treated as if it is a single component with some averaged parameters of the individual components. However, this approach leads to discontinuities in the isotherms. A new approach that avoids this problem is suggested and demonstrated.

C 2021 by the authors. Licensee MDPI, Basel, Switzerland. This article is an open access article distributed under the terms and conditions of the Creative Commons Attribution (CC BY) license (http://creativecommons.org/licenses/by/4.0/). 